\title{
A NEW ICEBREAKER FOR INLAND WATER CONCEPT
}

\author{
Liviu Andrei MOISE \\ "Dunarea de Jos" University of Galati, \\ Faculty of Naval Architecture, Galati, Domneasca \\ Street, No. 47, 800008, Romania, \\ E-mail: liviu.moise@ugal.ro

\section{Eugen GAVAN} \\ "Dunarea de Jos" University of Galati, \\ Faculty of Naval Architecture, Galati, Domneasca \\ Street, No. 47, 800008, Romania, \\ E-mail: eugen.gavan@ugal.ro
}

\author{
Gabriela Alexandra ALBU \\ "Dunarea de Jos" University of Galati, \\ Faculty of Naval Architecture, Galati, Domneasca \\ Street, No. 47, 800008, Romania, \\ E-mail: albugabriela1@gmail.com \\ Costel Iulian MOCANU \\ "Dunarea de Jos" University of Galati, \\ Faculty of Naval Architecture, Galati, Domneasca \\ Street, No. 47, 800008, Romania, \\ E-mail: costel.mocanu@ugal.ro
}

\begin{abstract}
Considering last year's climate changes, we can expect low temperatures during winter, which can lead to the freezing of Danube river and more. This would prevent the freight traffic in Danube's ports meaning that the riparian economy would suffer. This paper presents a new concept of breaking the ice. Using an existent tug, we propose the attachment of an icebreaking additional structure. The paper further describes the concept and includes the necessary calculation methods used for the technological design of this ensemble. This concept presents numerous advantages, including the financial aspect.
\end{abstract}

Keywords: ice breaker, concept, structural analysis.

\section{INTRODUCTION}

Currently, the ice breaking operation on inland waters is realised with specialised ships. These icebreakers are active only in the winter season, spending the rest of the year at the quay. Considering the necessity of a permanent crew on board (the abandon of the ship role has to be respected as specified in the international conventions), the costs of energy and other necessities are not justified for the entire year.

Starting from this fact, the paper is proposing a concept of an additional structure, which connected to an inland tug, transforms it into a ship capable of breaking the ice on inland waters.

The concept is based on a tug vessel of enough power reserve to operate in ice infested waters and/or in localised drift ice.
This removable icebreaking bow can be with or without propulsion. This study analyses the behaviour of an additional structure without propulsion.

This paper contains the shape of the structure, the attachment method to the tug's hull, the modification of the fore part of the tug's hull for strengthening the area of connection and also the analysis of stresses and strains that appear on the tug's hull and on the additional structure's hull.

\section{CONCEPT}

Considering that the additional structure constitutes a casing for the tug's bow, the designed shape has to respect that desideratum. The aft part of the removable bow will have a shape similar to the shape of the tug's bow. 
From the beginning, a distance of $500 \mathrm{~mm}$ was considered between the two structures as a safety measure, considering a series of factors:

- the additional structure cannot touch the tug's hull during its jigging motion;

- the connection between these structures is accomplished through a rigid massive element;

- localised drift ice cannot enter the empty space between the hulls since it would block the jigging motion of the removable bow.

The connection of the two structures is made with two massive cast steel elements that will be mechanically processed: a throat bolt

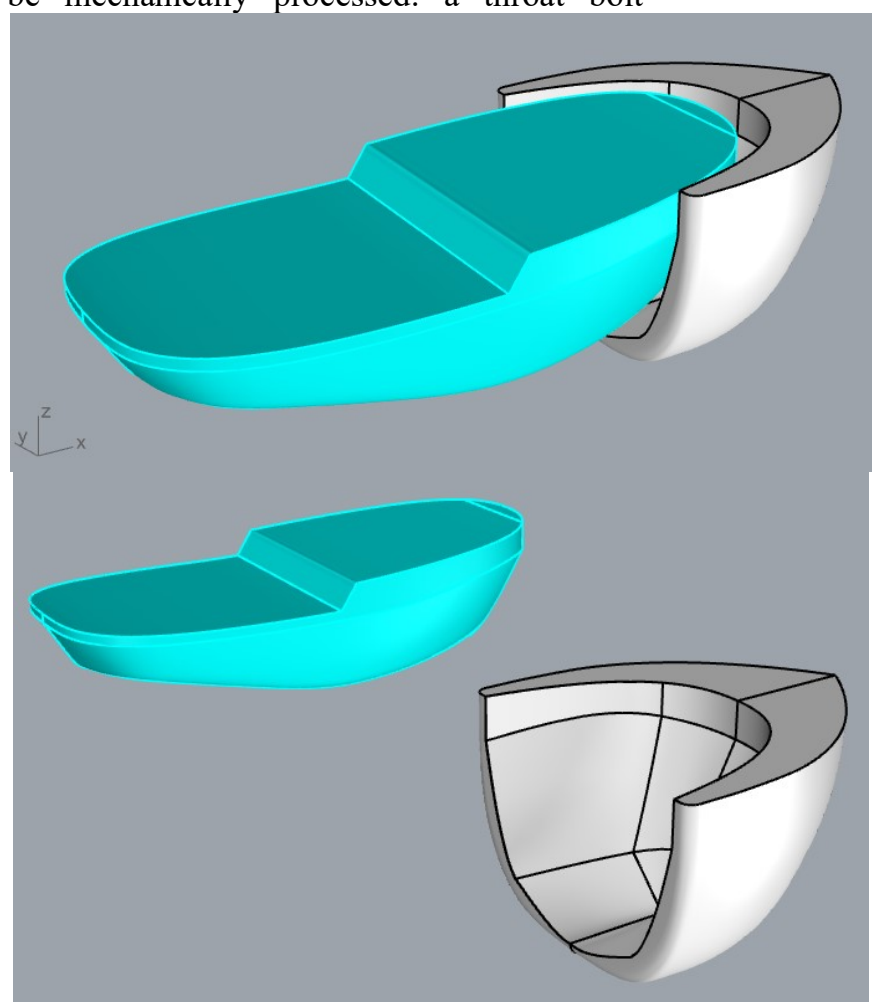

Figure 1 mounted in the tug's structure and an element in which the bolt is fixed on the exterior of the additional structure's hull.

The concept of the tug - additional icebreaking structure system is presented in figure 1.

As the figure illustrates, the hulls are completely independent and they are connected to each other only if necessary, so that the tug can fulfil its operating functions in port roads. 

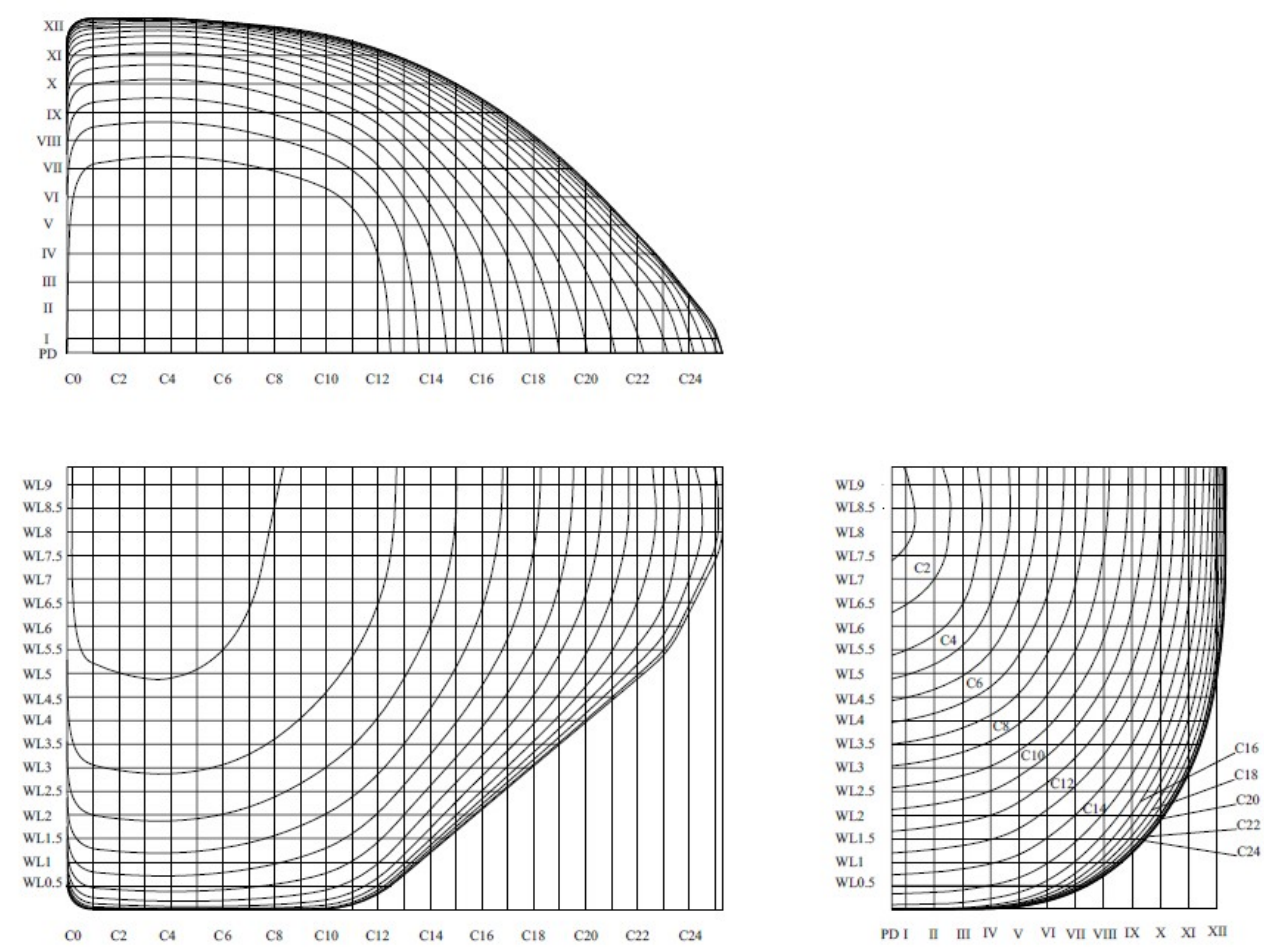

Figure 2

\subsection{Hydrostatics}

The body plan is further used for the hydrostatic curves' calculus. The hydrostatic curves diagram is presented in figure 3 .

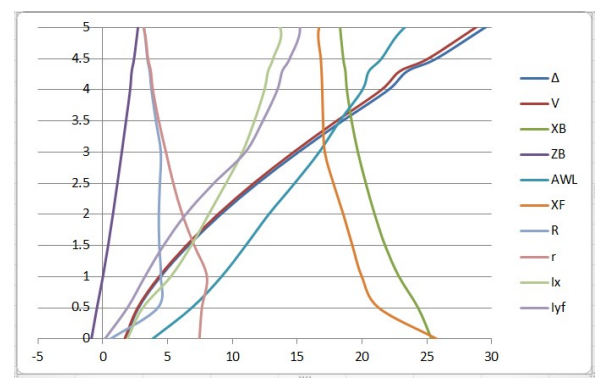

Figure 3

The principal dimensions of the ensemble tug - additional structure (struct) are given in table 1 .
One of the main issues of this calculus is determining the ship's resistance.

Table 1

\begin{tabular}{|c|r|r|r|}
\cline { 2 - 4 } \multicolumn{1}{c|}{} & \multicolumn{1}{c|}{ Tug } & \multicolumn{1}{c|}{ Struct } & \multicolumn{1}{c|}{ Complex } \\
\hline \multirow{2}{*}{ Name } & \multicolumn{3}{c}{} \\
& \multicolumn{2}{c}{} \\
\hline Loa & 28.1 & 13.9 & 35.5 \\
\hline Lwl & 27.8 & 13.7 & 34.6 \\
\hline $\mathrm{D}$ & 5.35 & 9.4 & 7.4 \\
\hline $\mathrm{B}$ & 12.6 & 14 & 14 \\
\hline $\mathrm{T}$ & 4.3 & 6.2 & 4.3 \\
\hline $\mathrm{s}$ & 550 & 550 & 550 \\
\hline $\mathrm{X}_{\mathrm{B}}$ & 14.1 & 27.2 & 18.2 \\
\hline$\Delta$ & 825 & 375 & 1200 \\
\hline
\end{tabular}




\subsection{Ship's resistance}

In this case, the ship's resistance was determined with the Holtrop-Mennen method, by transposing the ensemble's dimen- sions in a software from the endowment of the Naval Hydrodynamics Research Center.

The characteristic values obtained are given in table 2.

Table 2

\begin{tabular}{|c|c|c|c|c|c|c|c|}
\hline $\begin{array}{c}\mathbf{V} \\
{[\mathbf{k n}]}\end{array}$ & $\begin{array}{c}\text { Thrust } \\
{[\mathbf{k N}]}\end{array}$ & $\begin{array}{c}\mathbf{R t} \\
{[\mathbf{k N}]}\end{array}$ & $\begin{array}{c}\text { PE } \\
{[\mathbf{k W}]}\end{array}$ & $\mathbf{w}$ & $\mathbf{t}$ & ETAH & ETAR \\
\hline 9.7 & 81.82 & 72.07 & 359.63 & 0.12 & 0.12 & 1 & 1.01 \\
\hline
\end{tabular}

\subsection{Structural arrangement}

To achieve its purpose, the removable bow structure must comply with the classification society rules for icebreaking ships. Therefore, the sizing of the structural arrangement was realised using DNV-GL rules for classification of ships. Thus, the ship's fore part was divided in areas reflecting the magnitude of the ice loads. The hull area divisions are presented in figure 4 .

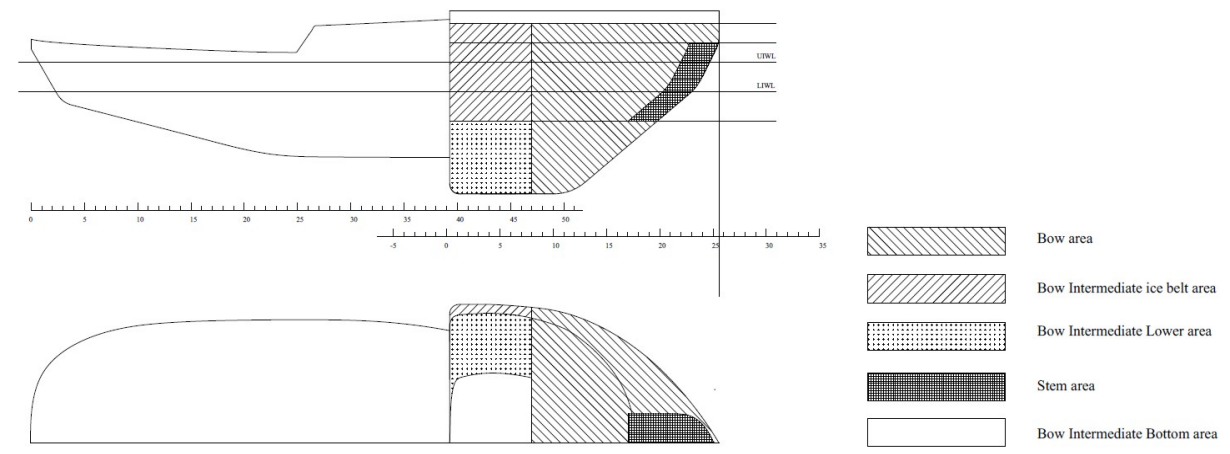

Figure 4

Following the sizing calculus, a midship section of the additional structure was provided in figure 5a. An isometric view of the designed structural arrangement is given in figure $5 \mathrm{~b}$.

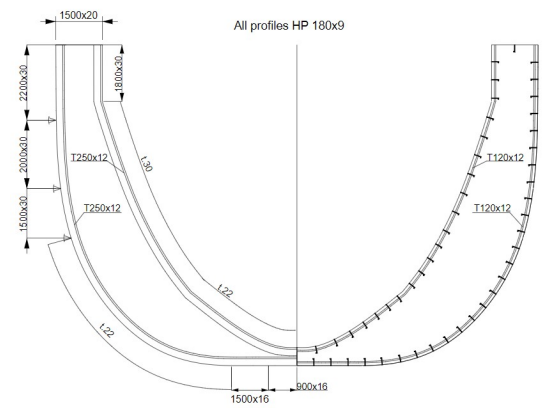

a)

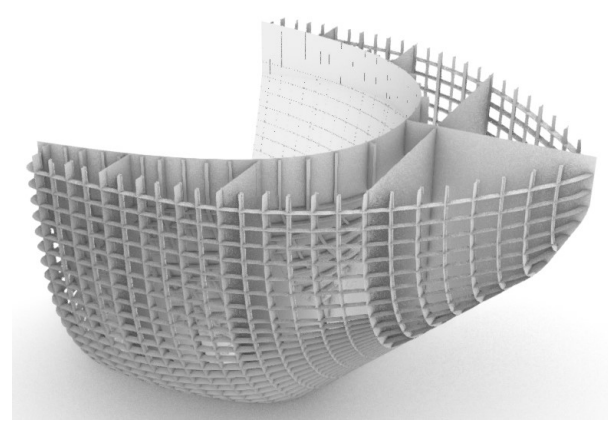

b)

Figure 5

The sizing calculus is further used to determine the additional structure's total mass. The mass value obtained for the 
removable bow structure is $177,9 \mathrm{t}$. Considering the tug's mass value is $298 \mathrm{t}$, the additional structure's mass represents $67.51 \%$ of the tug's mass.

For the connection of the two structures a bolt - connection element system is designed to be mounted on the tug's structure respectively on the removable bow's structure. The designed connection system is presented in figure 6 .

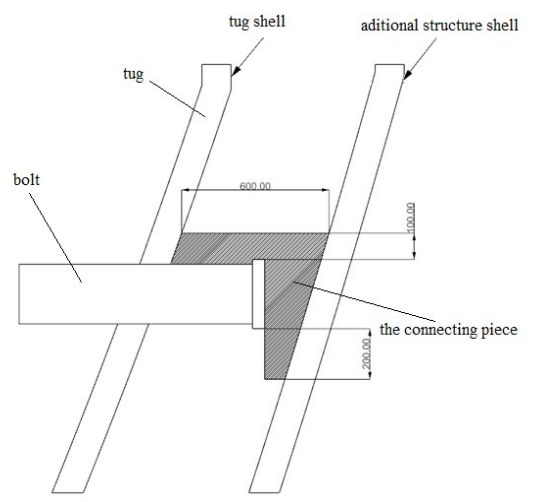

Figure 6

\section{ANALYSIS OF STRESSES AND STRAINS THAT APPEAR IN THE TUG'S BOW STRUCTURE}

As it was stated in the introduction, the ensemble is made of an existent tug (Damen 2910 type) to which is attached the additional icebreaking structure. In order to verify if by attaching the removable bow, the tug's fore structure resists, a stress analysis is necessary. After strengthening the bolt mounting area, the meshing of the tug's structure was realised for the analysis of stresses and strains with the finite element analysis software, FEMAP. The areas strengthened for mounting the bolt are presented in figure 7. The tug's strengthened area is given in figure $7 \mathrm{a}$ and the additional structure's strengthened area in figure $7 \mathrm{~b}$.

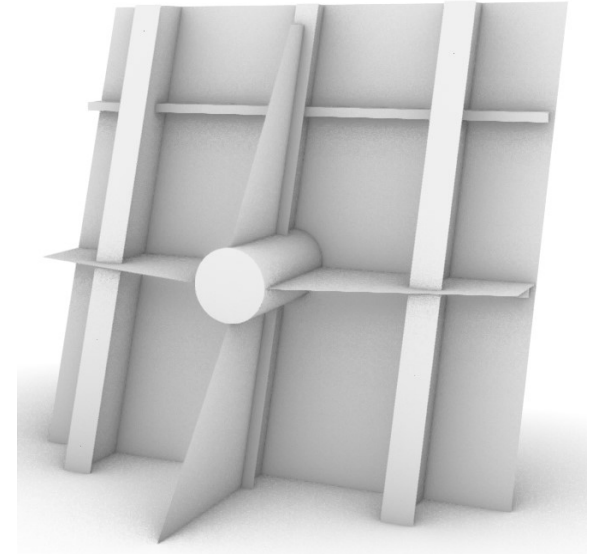

a)

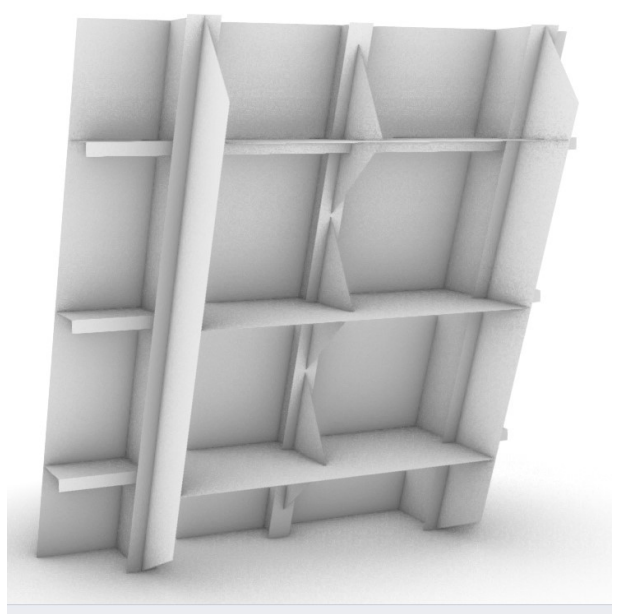

b)

Figure 7

The mesh area is presented in figure $7 \mathrm{a}$. The mesh was realised using shell elements with 8 degrees of freedom.

The tug's bow structure mesh is given in figure 8 . The structure's connections can be observed in figure $8 \mathrm{c}$. The contour of the structure was considered constrained, thus resembling reality as the strengthening of the stiffened area. 


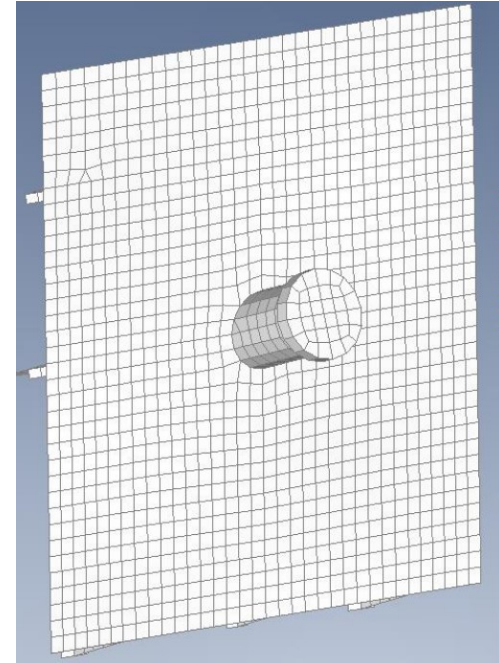

a)

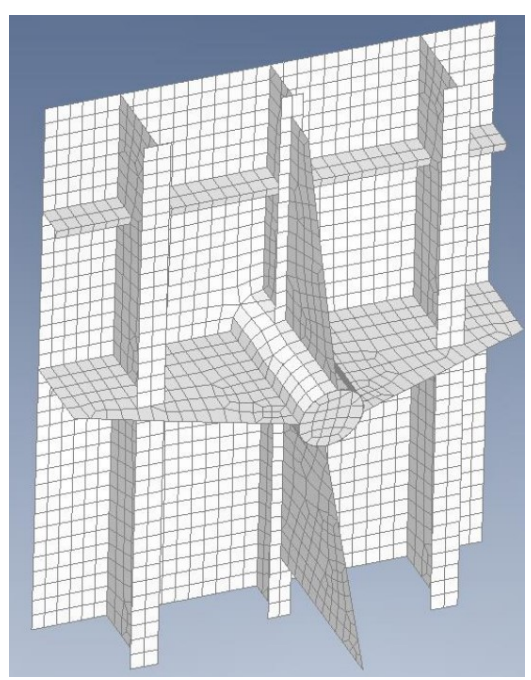

b)

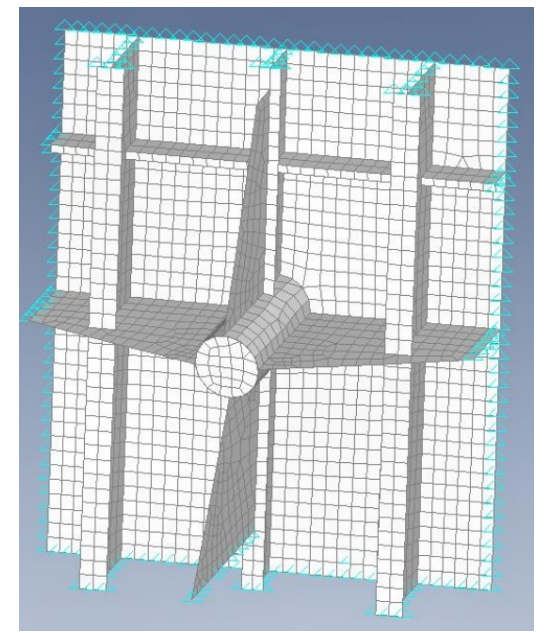

c)

The calculus results obtained are presented in figure 9. As shown, the maximum stress value of around $130 \mathrm{MPa}$ is well below the allowable value of the material used for the tug's structure. This area being under stressed means that it is sufficiently well stiffened. The total displacements are also found at low values: $0,6 \mathrm{~mm}$. 

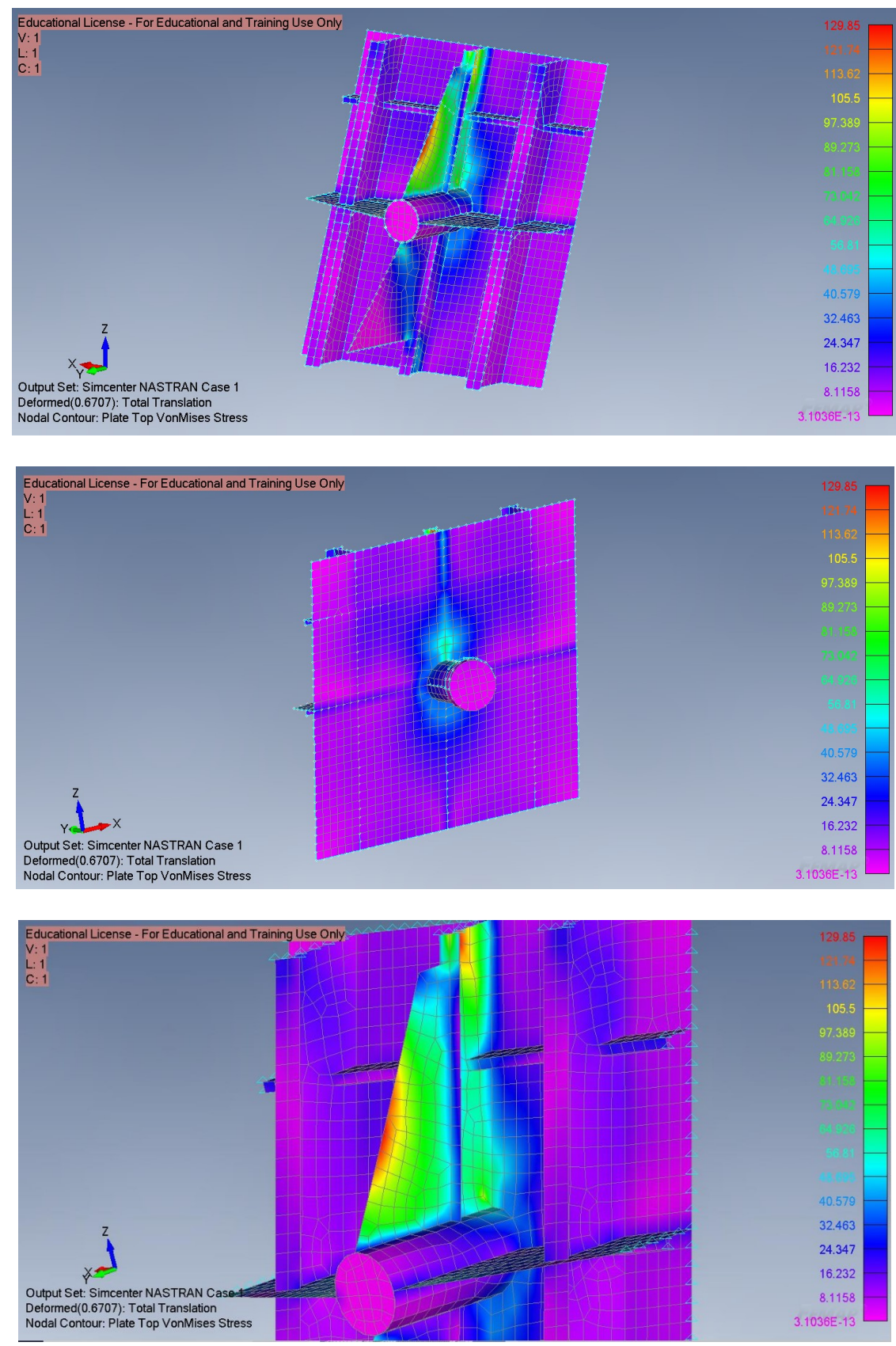

a) Von Mises Stress 

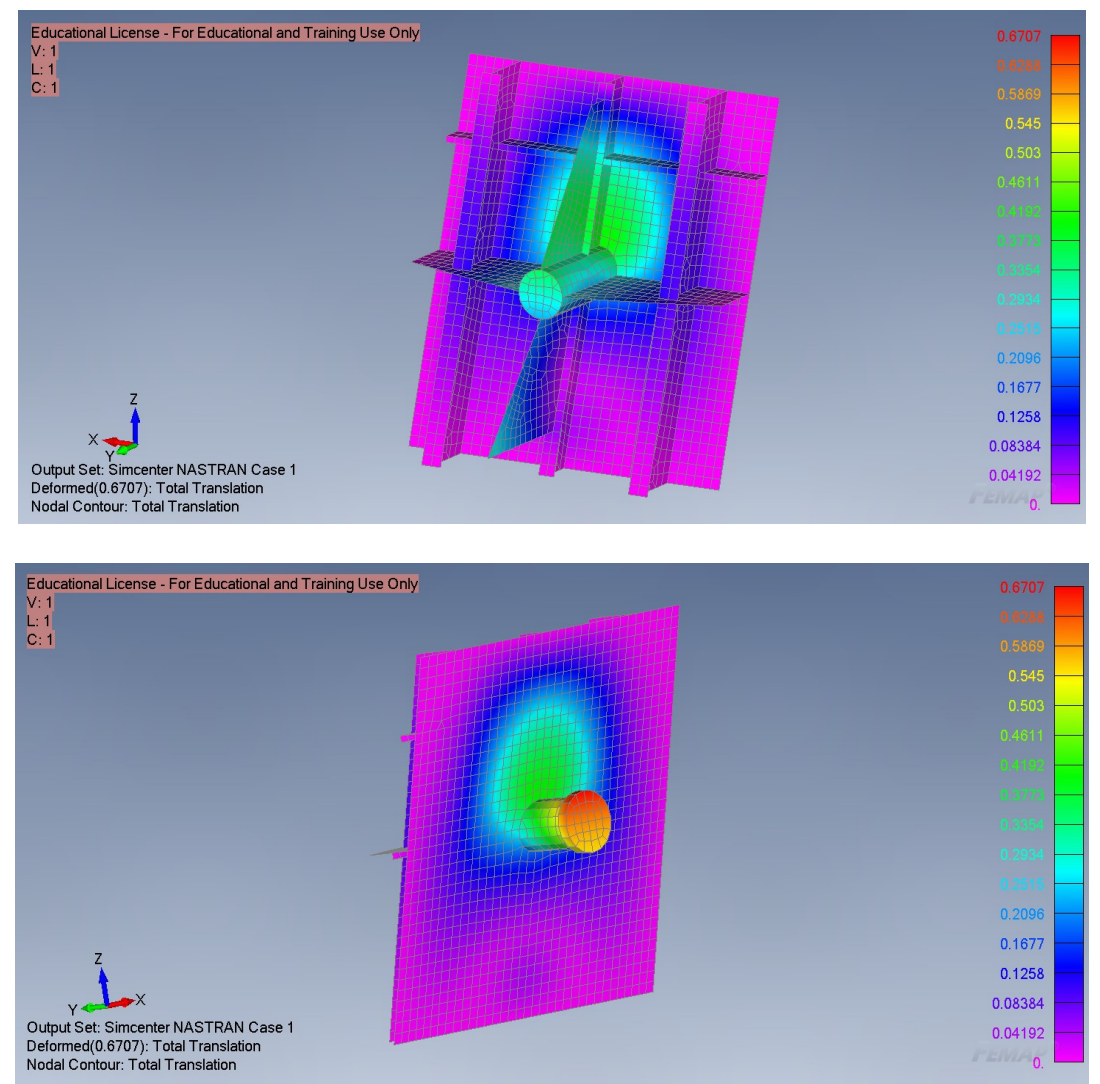

b) Total Translation

Figure 9

\section{CONCLUSIONS}

The inland icebreaking ensemble proposed in this paper, provides economic advantages, and meets the resistance criteria required for this type of ships.

The stress and strain values obtained from the numerical analysis are within the allowable limits for such floating structures. This concept can be easily configured so that the operation is simple and qualified staff is not necessary on board.

This concept can be implemented by the companies owning inland tugboats.

\section{BIBLIOGRAPHY}

[1] Leonard Domnișoru - Metoda elementului finit în construcții navale, Editura „Tehnică"

[2] - Finite element method - Fundamental concepts; http://www.resist.pub.ro

[3] - https://en.wikipedia.org/wiki/Tugboat

Paper received on August $31^{\text {th }}, 2020$ 